\title{
Myrica rubra Fruit Drink Sub-Chronic Toxicity and Hepatoprotective Effect in Rats
}

\author{
Badraddin Mohammed Al-Hadiya ${ }^{1}$, Mohamed Fahad AlAjmi ${ }^{2 *}$ and Kamal Eldin Hussein El Tahir ${ }^{3}$ \\ ${ }^{1}$ Departments of Pharmaceutical Chemistry, College of Pharmacy, King Saud University, Riyadh, Saudi Arabia \\ ${ }^{2}$ Departments of Pharmacognosy, College of Pharmacy, King Saud University, Riyadh, Saudi Arabia \\ ${ }^{3}$ Departments of Pharmacology, College of Pharmacy, King Saud University, Riyadh, Saudi Arabia
}

\begin{abstract}
Background: This study dealt with the effect of the subchronic toxicity of Myrica rubra fruit beverage drink $(\mathrm{MRD})$ in rats and its hepatoprotective effect against carbon tetrachloride $\left(\mathrm{CCl}_{4}\right)$-induced hepatotoxicity.

Methodology: Different groups of normal male and female Wistar rats were treated with 50\% MRD as drinking vehicle (13 weeks), as substitution of the normal drinking water. Coulter Counter was used for red blood corpuscles (RBCs) and white blood corpuscles (WBCs) count. The Reflotron instrument and Reflotron haemoglobin kit used for determination of haemoglobin content, while the Reflotron strips for determination of blood glucose, total triglycerides and cholesterol contents, blood enzymatic levels, and bilirubin. Atomic absorption spectroscopy was used for determination of blood $\mathrm{Na}^{+}, \mathrm{Mg}^{++}$and $\mathrm{Ca}^{++}$concentrations.

Principal findings: Treatment induced significant increases in the red blood corpuscles (RBCs) count, haematocrit and haemoglobin content. It also significantly decreased plasma levels of total cholesterol and the low-density lipoproteins (LDL) without affecting the levels of high-density lipoproteins (HDL), glucose, triglycerides and bilirubin, together with the significant decrease in hepatic malonaldehyde production. The treatment resulted in significant reductions in the enzymes alanine transiminase (ALT), aspartate aminotransferase (AST) and Alkaline phosphatase (ALP) and a significant diuretic effect.
\end{abstract} food.

Conclusion: The results of the study point to the potential of Myrica rubra fruit drink to act as a new functional

Keywords: Myrica rubra drink; Hepatoprotection; Hepatotoxicity; Hepatic enzymes

\section{Introduction}

Myrica rubra or Bayberry, Yumberry, Waxberry or Chinese strawberry tree is usually cited as Myrica rubra by Siebold and Zuccarini (1846).

Myrica rubra sieb et zucc. fruits, family Myricaceae, are stony red fruits with berry-like edible portions. The fruit is grown in China, India, Japan and some other south eastern Asian countries such as, Vietnam, Burma and Thailand. It is known by various other names such as Yangmei, Bayberry and Chinese arbutus. It is also known as Waxmytle and Yamamoto in Japan.

Phytochemical investigations of the fruit juice revealed the presence of high concentrations of polyphenols and proanthocyanidins [1]. The latter are condensed tannins (polymers) composed of various flavan3-ol or catechin units. The most available are the reddish procyanidins [2]. In addition to the fruits both of the leaves and the bark of the tree constituents were analyzed [3-5].

The proanthocyanidins were reported to possess various actions that included antioxidant [6,7], anti-viral [7,8], hypolipidemic [9], anticancer [10], and anti-inflammatory actions [11].

Myrica rubra juice is now widely distributed world-wise as a $50 \%$ refreshing drink and also as a carbonated beverage - under the trade name Yumberry. Thus, it was thought of interest to investigate the outcomes of the sub-chronic toxicity (treatment for 13 weeks) of this refreshing drink. When it was observed that it decreases some hepatic enzymes, it was thought to investigate the effect of short term treatment of rats (4 weeks) with the drink as a sole source of drinking vehicle.

\section{Materials and Methods}

\section{Yumberry juice drink}

Yumberry juice bottled drink was purchased from the local market in Riyadh city, Kingdom of Saudi Arabia. The bottled drink is a product of China (Zhejiang Yumberry Juice Co.).

\section{Animals}

In this study male Wistar rats (body weight $250 \pm 10 \mathrm{~g}$ ) and females ( $220 \pm 8 \mathrm{~g}$ ) were used. The animals were provided with standard chow diet, supplied by Silo and Flour Mills Organization, Feed Mill, Riyadh, Saudi Arabia. All animals were housed at a temperature of $22^{\circ} \pm 1^{\circ} \mathrm{C}$ and relative humidity of $50 \pm 5 \%$. The light: dark cycle was 12 hours each. The animals' treatment was conducted in accordance with the Guide for the Care and Use of Laboratory Animals. The protocol of the current study was approved by the ethics Committee of the College of Pharmacy, King Saud University, Riyadh, KSA.

*Corresponding author: Mohamed FahadAIAjmi, Departments of Pharmacognosy, College of Pharmacy, King Saud University, Riyadh, Riyadh 11451, P.O. Box 2457, Saudi Arabia, Tel: 00966 505151846; E-mail: malajmii@ksu.edu.sa

Received January 05, 2013; Accepted January 30, 2013; Published February 01, 2013

Citation: Al-Hadiya BM, AIAjmi MF, El Tahir KEH (2013) Myrica rubra Fruit Drink Sub-Chronic Toxicity and Hepatoprotective Effect in Rats. Adv Pharmacoepidem Drug Safety 2: 127. doi:10.4172/2167-1052.1000127

Copyright: (c) 2013 Al-Hadiya BM, et al. This is an open-access article distributed under the terms of the Creative Commons Attribution License, which permits unrestricted use, distribution, and reproduction in any medium, provided the original author and source are credited. 


\section{Treatment of the animals}

The control group was allowed tap water ad lib. The treatment group was administered Myrica rubra juice refreshing drink (50\% Yumberry drink) as the sole source of drinking vehicle for 13 weeks in case of the sub-chronic toxicity and for 4 weeks in the case of the Hepatoprotective activity.

To investigate the hepatoprotective effects, carbon tetrachloride $\mathrm{CCl}_{4}$ was used as an inducer of hepatotoxicity. For this purpose, it was administered as a mixture of $\mathrm{CCl}_{4}$ : paraffin oil in the ratio of $1: 1$ at a dose of $1 \mathrm{ml} / \mathrm{kg}$ intraperitoneally (i.p). Male Wistar rats were divided into 3 groups ( $\mathrm{N}=8$ animals per group). Group No. 1 was injected with paraffin oil only ( $1 \mathrm{ml} / \mathrm{kg}$ intraperitoneally) as a single dose. Group 2 was injected with the mixture of $\mathrm{CCl}_{4}$ and paraffin oil. Group 3-the one given Yumberry drink for 4 weeks-was administered the mixture of $\mathrm{CCl}_{4}$ and paraffin oil as a single dose $(1 \mathrm{ml} / \mathrm{kg}$ i.p. $)$ in the morning following the 4 -week-treatment period. Blood was collected on the third day.

\section{Collection of blood from the sub-chronically-treated and control animals}

On days 90 and 91 following the start of the treatment, the animals were anaesthetized with diethyl ether and blood $(7 \mathrm{ml})$ was collected from each control and treated animal using cardiac puncture employing a 23 -gange needle fitted to a $10-\mathrm{ml}$ plastic syringe. $1 \mathrm{ml}$ from each animal was used for determination of the various blood cell counts, the hemoglobin content and the clotting times. The remaining blood (6 ml each) was mixed with $3.6(\mathrm{w} / \mathrm{v})$ aqueous trisodium citrate solution in the ratio of 1:9 (citrate:blood) to prevent blood clotting. The blood was then centrifuged at $3000 \mathrm{rpm}$ (EMS Centrifuge) for 20 minutes to obtain platelets and blood cells-free plasma and to calculate the haematocrit value for each animal. The latter were corrected for the added trisodium citrate. The plasma was then stored at $-20^{\circ} \mathrm{C}$ until used within the next few days for the determination of the various parameters indicated below.

\section{Determination of blood cell counts}

The numbers of RBCs and WBCs per $\mu$ l whole blood obtained from each control or treated rat was determined using Coulter Counter, Model S8 90 (Coulter Electronics, Lubon beds, U.K.). The volume of blood used was $125 \mu \mathrm{l} /$ test.

\section{Determination of haemoglobin content}

The haemoglobin content was determined using the Reflotron Instrument and Reflotron haemoglobin kit (Roche Diagnostic GmbH, D-68298, Mannheim, Germany). The test depends upon conversion of haemoglobin to methaemoglobin in presence of potassium ferricyanide as outlined by Van Assendelft [12].

\section{Determination of the haematocrit value}

The haematocrit value of each blood sample was calculated following the centrifugation of the collected blood in graduated centrifuge tubes at $3000 \mathrm{rpm}$ (EMS Centrifuge) for 20 minutes.

\section{Determination of blood glucose level}

The concentration of glucose was determined in each cell-free plasma using the Reflotron Instrument and the Reflotron Glucose strip (Roche Diagnostics). It depends upon the principle of conversion of glucose in the sample in presence of molecular oxygen and the enzyme GOD (Glucose Oxidase Dehydrogenase to S-D-gluconolactone and $\mathrm{H}_{2} \mathrm{O}_{2}$. The latter in presence of the indicator 3,3,5,5-tetramethyl benzidine and the enzyme POD (peroxidase 'horseradish') gives a color which was measured as outlined by Trasch [13].

\section{Determination of blood total cholesterol}

The cholesterol contents in the different plasmas were determined using the Reflotron instrument and the Reflotron strips (Roche Diagnostics) depending upon the principle of conversion of the blood cholesterol esters to cholesterol in presence of the enzyme cholesterol esterase. The produced cholesterol is then converted in presence of molecular oxygen and cholesterol Oxidase to cholestenone and $\mathrm{H}_{2} \mathrm{O}_{2}$. The latter in presence of the indicator 3,3,5,5-tetramethyl benzidine and the enzyme POD (peroxidase 'horseradish') gives a color which was measured as outlined by Braun [14].

\section{Determination of blood total triglycerides}

The triglycerides contents of the different plasmas were determined using the Reflotron Instrument and the provided strips (Roche Diagnostics). The method depends upon the principle of conversion of the blood triglycerides in presence of the enzyme esterase to glycerin and fatty acids. The produced glycerin in presence of ATP and the enzyme glycerin kinase I is then converted to glycerin-3phosphate and ADP. The glycerin-3-phosphate is then acted on by the enzyme glycerin phosphate Oxidase and molecular oxygen to produce dihydroxyacetone phosphate and $\mathrm{H}_{2} \mathrm{O}_{2}$. The latter in presence of the indicator 4-(4-dimethylaminophenyl) 5-methyl-2-(3,5-dimethoxy4-hydroxyphenyl) imidazole dihydrochloride and the enzyme POD (Peroxide 'horse radish') produces a color which can be measured as outlined by Carstensen et al. [15].

\section{Determination of blood GOT (AST) (Glutamic oxaloacetic acid transiminase or Aspartate aminotransferase)}

The levels of AST in the different plasmas were determined using Reflotron Instrument and the provided strips (Roche Diagnostics, Germany). The principle depends upon the ability of the enzyme GOT to act on ketoglutarate and alanine sulfinate to produce glutamate and pyruvate. The latter in presence of molecular $\mathrm{O}_{2}$, phosphate ions and water is acted on by the enzyme pyruvate Oxidase to $\mathrm{CO}_{2}$, acetyl phosphate and $\mathrm{H}_{2} \mathrm{O}_{2}$. The latter in presence of the peroxidase enzyme and the indicator 4-(4-dimethyl aminophenyl) 5-methyl-2-(3, 5-di-tbutyl-4-hydroxyphenyl) imidazole dihydrochloride gives a blue color which intensity can be measured as outlined by Denake [16].

\section{Determination of blood ALT (Alanine Transiminase) or GPT (Glutamate- Pyruvate Transiminase)}

The concentrations of the ALT in the different plasmas were determined using the Reflotron Instrument and the provided strips (Roche Diagnostics, Germany). The principle depends upon the ability of ALT to convert ketoglutarate and alanine to glutamate and pyruvate. The latter in presence of $\mathrm{PO}_{4}^{2-}$, water and molecular oxygen is then converted by the enzyme pyruvate Oxidase to acetyl phosphate, $\mathrm{CO}_{2}$ and $\mathrm{H}_{2} \mathrm{O}_{2}$. The latter in presence of the enzyme peroxidase and the indicator 4-(4-dimethyl aminophenyl) 5-methyl-2-(3, 5-di-t-butyl4-hydroxyphenyl) imidazole dihydrochloride produces a blue color, which color intensity, can be measured as outlined by Denake and Rittersdorf [17]. 
Citation: Al-Hadiya BM, AlAjmi MF, El Tahir KEH (2013) Myrica rubra Fruit Drink Sub-Chronic Toxicity and Hepatoprotective Effect in Rats. Adv Pharmacoepidem Drug Safety 2: 127. doi:10.4172/2167-1052.1000127

Page 3 of 5

\section{Determination of blood alkaline phosphatase}

The contents of alkaline Phosphatase in the different plasmas were determined using Reflotron Instrument and the provided strips (Roche Diagnostics). The principle depends upon the ability of the enzyme alkaline Phosphatase to convert o-cresophthalein phosphate and methylglucamine to methylglucamine phosphate and the colored compound o-cresophthalein that can be measured at $567 \mathrm{~nm}$ as outlined by Rosalki and Heins $[18,19]$.

\section{Determination of blood $\mathrm{K}^{+}$}

The concentrations of $\mathrm{K}^{+}$in the different plasmas were determined using Reflotron Instrument and the provided strips (Roche Diagnostics). The principle depends upon the interaction and complexation of $\mathrm{K}^{+}$in the plasmas with valinomycin and the indicators 4-[(2,6-dibromo-4nitrophenyl) azo]-2-naphthol to give a colored complex that can be measured as outlined by Lum and Cambizzino [20].

\section{Determination of blood bilirubin}

The concentrations of bilirubin in the different plasmas were determined using the Reflotron Instrument and provided strips (Roche Diagnostics). The principle depends upon the interaction of blood bilirubin with the indicator 2-methoxy-4-nitrophenyl diazonium tetrafluroborate to produce the colored product azobilirubin as outlined by Freitag [21].

\section{Determination of blood $\mathrm{Na}^{+}, \mathrm{Mg}^{++}$and $\mathrm{Ca}^{++}$}

The concentrations of $\mathrm{Na}^{+}, \mathrm{Mg}^{++}$and $\mathrm{Ca}^{++}$in the different plasmas were determined using atomic absorption spectroscopy using Varian AA775, atomic absorption spectrophotometer. For the determination of $\mathrm{Na}^{+}$the fixed working conditions were: Lamp current $5 \mathrm{~mA}$, fuel: acetylene support air and flame stoichiometry: oxidizing. In the flame emission the wavelength used was $589.0 \mathrm{~nm}$, the spectral band pass was $0.1 \mathrm{~nm}$, the fuel: acetylene and the support: air.

For the determination of magnesium $\left(\mathrm{Mg}^{++}\right)$the fixed working conditions were: lamp current $3.5 \mathrm{~mA}$, fuel: acetylene, support: air and flame stoichiometry: oxidizing. The working flame emission conditions were: wavelength $285.2 \mathrm{~nm}$, spectral band pass $0.1 \mathrm{~nm}$, fuel: acetylene and support: nitrous oxide.

For the determination of $\mathrm{Ca}^{++}$, the fixed working conditions were: lamp current $3.5 \mathrm{~mA}$, fuel: acetylene, support: nitrous oxide and flame stoichiometry: reducing: red cone $1-1.5 \mathrm{~cm}$ high. The flame emission conditions were: wavelength $422.7 \mathrm{~nm}$, spectral band pass $0.1 \mathrm{~nm}$, fuel: acetylene and support: nitrous oxide [22,23].

\section{Determination of urinary $\mathrm{Na}^{+}, \mathrm{K}^{+}$and $\mathrm{Ca}^{++}$contents}

The concentrations of $\mathrm{Na}^{+}$and $\mathrm{Ca}^{++}$in urine were determined using atomic absorption spectrophotometry as described above. The concentrations of $\mathrm{K}^{+}$were determined using Reflotron Instrument and specific strips as described above. It should be noted that following collection of urines, they were acidified immediately after collection by the addition of concentrated $\mathrm{HCl}(1 \mathrm{ml}$ acid $+3 \mathrm{ml}$ urine) to prevent the precipitation of calcium oxalate and phosphate [24].

\section{Statistical analysis}

All values reported were the mean \pm standard error (s.e.) of mean. Statistical differences were examined using ANOVA techniques using the least significant difference criterion or the ' $t$ ' test as appropriate.

\section{Results}

General observations during the sub-chronic study regarding the general health of the animals

All animals treated with Myrica rubra drink (MRD) as the sole drinking vehicle for the whole 13 weeks were healthy. There were no any toxicological signs in the respiratory, cardiovascular, central and autonomic nervous system. There were no changes in the eyes.

\section{Water and food consumption}

Table 1 depicts the mean \pm s.e. mean drinking vehicles and food $/ \mathrm{kg} /$ week in the control and treated groups (males and females). The food and MRD consumed by the treated animals (both male and female rats) were significantly greater than that consumed by the corresponding control animals $(\mathrm{P}<0.05, \mathrm{~N}=8)$.

\section{Effect on blood cells, haematocrit and haemoglobin}

Table 2 depicts the effects of MRD treatment on total erythrocytes, leukocytes, platelets, haematocrit and haemoglobin content.

\section{Effect on blood glucose, blood lipids and bilirubin}

Treatment of both sexes of rats with MRD induced significant decreases in both total cholesterol and LDL $(\mathrm{P}<0.01, \mathrm{~N}=8)$ without any effect on glucose, HDL, triglycerides and bilirubin. Table 3 shows the cumulative results.

\section{Effect on liver enzymes}

Treatment of rats (both sexes) with MRD as the sole drinking

\begin{tabular}{|c|c|c|}
\hline \multirow{2}{*}{ Animal group (Sex) } & \multicolumn{2}{|c|}{ Mean Consumption/kg/week } \\
\cline { 2 - 3 } & Drinking Vehicle (ml) & Food (g) \\
\hline Control (Male) & $708 \pm 17.3$ & $541.3 \pm 12.6$ \\
\hline Control (Female) & $661 \pm 13.9$ & $480 \pm 16.3$ \\
\hline MRD (Male) & $879.9 \pm 15.1^{*}$ & $639.5 \pm 9.7^{*}$ \\
\hline MRD (Female) & $830 \pm 11.9^{*}$ & $576 \pm 9.3^{*}$ \\
\hline
\end{tabular}

${ }^{\star} \mathrm{P}<0.05, \mathrm{~N}=8$, compared with the corresponding control.

Table 1: Water and Food Consumption by Rats during Treatment with MRD.

\begin{tabular}{|c|c|c|c|c|c|}
\hline \multirow{2}{*}{$\begin{array}{l}\text { Treatment } \\
\text { (sex) }\end{array}$} & \multicolumn{3}{|c|}{ No. of Cells/ul Blood } & \multirow[t]{2}{*}{ Haematocrit } & \multirow{2}{*}{$\begin{array}{c}\text { Haemoglobin } \\
\mathrm{g} \%\end{array}$} \\
\hline & $\mathrm{RBC} \times 10^{6}$ & WBC $\times 10^{3}$ & Platelets $\times 10^{3}$ & & \\
\hline Control (male) & $9.1 \pm 0.07$ & $13.6 \pm 0.1$ & $301 \pm 0.2$ & $43.5 \pm 0.6$ & $14.1 \pm 0.1$ \\
\hline $\begin{array}{l}\text { Control } \\
\text { (female) }\end{array}$ & $7.8 \pm 0.03$ & $11.6 \pm 0.08$ & $285 \pm 0.1$ & $39.6 \pm 0.2$ & $13.5 \pm 0.08$ \\
\hline MRD (male) & $10.08 \pm 0.1^{*}$ & $13.9 \pm 0.2$ & $310 \pm 0.3$ & $48.3 \pm 1^{*}$ & $15.7 \pm 0.04^{*}$ \\
\hline MRD (female) & $8.75 \pm 0.07^{*}$ & $11.4 \pm 0.1$ & $291 \pm 0.2$ & $44.9 \pm 0.7^{*}$ & $14.8 \pm 0.05^{*}$ \\
\hline
\end{tabular}

${ }^{*} \mathrm{P}<0.01, \mathrm{~N}=8$, compared with the corresponding control.

Table 2: The effects of MRD treatment on total erythrocytes, leukocytes, platelets haematocrit and haemoglobin content.

\begin{tabular}{|c|c|c|c|c|c|c|}
\hline Parameter & \multicolumn{5}{|c|}{ mg \% } \\
\hline $\begin{array}{c}\text { Treatment } \\
\text { (sex) }\end{array}$ & Glucose & $\begin{array}{c}\text { Total } \\
\text { Cholesterol }\end{array}$ & LDL & HDL & Triglyceride & Bilirubin \\
\hline $\begin{array}{c}\text { Control } \\
\text { (Male) }\end{array}$ & $109 \pm 6.7$ & $99 \pm 5.3$ & $31.3 \pm 1.7$ & $49.6 \pm 2.3$ & $88.7 \pm 3.9$ & $0.3 \pm 0.01$ \\
\hline $\begin{array}{c}\text { Control } \\
\text { (Female) }\end{array}$ & $102 \pm 4.9$ & $86 \pm 3.9$ & $33.1 \pm 3.1$ & $41 \pm 3.5$ & $78 \pm 1.7$ & $0.25 \pm 0.02$ \\
\hline $\begin{array}{c}\text { MRD } \\
\text { (Male) }\end{array}$ & $116 \pm 9.1$ & $87.9 \pm 3.4^{*}$ & $25.9 \pm 2.1^{*}$ & $48.9 \pm 1.9$ & $85.1 \pm 2.3$ & $0.29 \pm 0.02$ \\
\hline $\begin{array}{c}\text { MRD } \\
\text { (Female) }\end{array}$ & $108 \pm 7.3$ & $75.1 \pm 4.2^{*}$ & $28 \pm 1.3^{*}$ & $43 \pm 1.7$ & $80 \pm 2.5$ & $0.23 \pm 0.01$ \\
\hline
\end{tabular}

${ }^{*} \mathrm{P}<0.01, \mathrm{~N}=8$, compared with the corresponding control.

Table 3: Effect of MRD on Blood Lipids, Glucose, Triglycerides and Bilirubin. 


\begin{tabular}{|c|c|c|c|}
\hline Parameter & \multicolumn{3}{|c|}{ U/litre Plasma } \\
\hline Treatment (sex) & ALT & AST & Alkaline Phosphatase \\
\hline Control (Male) & $27.4 \pm 1.3$ & $65.0 \pm 3.9$ & $95.0 \pm 1.6$ \\
\hline Control (Female) & $24.9 \pm 0.9$ & $55.0 \pm 4.1$ & $83.0 \pm 0.9$ \\
\hline MRD (Male) & $21.1 \pm 0.7^{*}$ & $51.5 \pm 3.2^{*}$ & $79.8 \pm 4.2^{*}$ \\
\hline MRD (Female) & $21.5 \pm 1.1^{*}$ & $44.5 \pm 1.7^{*}$ & $68.9 \pm 2.9^{*}$ \\
\hline
\end{tabular}

$\mathrm{P}<0.05, \mathrm{~N}=8$ compared with its respective control

Table 4: Effect of MRD on hepatic enzymes in rats.

\begin{tabular}{|c|c|c|c|c|c|}
\hline Parameter & \multicolumn{3}{|c|}{ U/Litre (Plasma) } & $\begin{array}{c}\text { mg \% } \\
\text { (Plasma) }\end{array}$ & $\begin{array}{c}\mu m o l e / g \\
\text { liver tissue }\end{array}$ \\
\hline Treatment & ALT & AST & $\begin{array}{c}\text { Alkaline } \\
\text { Phosphatase }\end{array}$ & Bilirubin & $\begin{array}{c}\text { Malon- } \\
\text { aldehyde }\end{array}$ \\
\hline $\begin{array}{c}\text { Control } \\
\text { (paraffin oil) }\end{array}$ & $29.3 \pm 0.9$ & $70.0 \pm 3.8$ & $90.0 \pm 6.1$ & $0.3 \pm 0.1$ & $1.1 \pm 0.09$ \\
\hline $\mathrm{CCl}_{4}$ & $91.7 \pm 3.1$ & $190.0 \pm 6.9$ & $261.0 \pm 7.3$ & $0.8 \pm 0.2$ & $3.7 \pm 0.2$ \\
\hline $\mathrm{MRD}^{*}$ & $52.1 \pm 2.9^{*}$ & $133.2 \pm 11.3^{*}$ & $188.0 \pm 4.9^{*}$ & $0.58 \pm 0.1^{*}$ & $1.6 \pm 0.15^{*}$ \\
\hline
\end{tabular}

${ }^{*} \mathrm{P}<0.01, \mathrm{~N}=8$ compared with $\mathrm{CCl}_{4}$-treated animals.

Table 5: Effect of MRD on carbon tetrachloride-induced hepatotoxicity in male rats.

vehicle for 13 weeks induced significant decreases in ALT, AST and alkaline phosphatase enzymes $(\mathrm{P}<0.05, \mathrm{~N}=8)$. Table 4 depicts the cumulative results.

\section{Effect on blood ions}

The blood levels of $\mathrm{Na}^{+}, \mathrm{K}^{+}, \mathrm{Ca}^{++}$and $\mathrm{Mg}^{++}$in the control male rats were $142 \pm 0.9,4.8 \pm 0.03,2.45 \pm 0.03$ and $0.9 \pm 0.1 \mathrm{mmole} / \mathrm{litre}$, respectively. The corresponding values in female rats were $133 \pm 1.9,4.6$ $\pm 0.1,2.3 \pm 0.1$ and $0.8 \pm 0.07$ mmole/litre. Treatment with MRD did not induce any significant changes in these levels.

\section{Effect on urine production and the urinary concentrations of $\mathrm{Na}^{+}, \mathrm{K}^{+}$and $\mathrm{Ca}^{++}$ions}

Treatment of both sexes of rats with MRD significantly increased the volume of urine voided from $3.95 \pm 0.07 \mathrm{ml}$ (male control) to 5.1 $\pm 0.1 \mathrm{ml}$ and from $3.36 \pm 0.04 \mathrm{ml}$ (female control) to $4.51 \pm 0.08 \mathrm{ml}$ $(\mathrm{P}<0.05, \mathrm{~N}=8)$. The treatment increased the excretion of $\mathrm{Na}^{+}$from 0.128 \pm 0.01 (control male) to $0.139 \pm 0.02 \mathrm{mmole} / \mathrm{litre}$ and from $0.114 \pm 0.03$ (control female) to $0.123 \pm 0.04 \mathrm{mmole} /$ litre. These were insignificant increases $(\mathrm{P}>0.05, \mathrm{~N}=8)$. There were no significant changes in both $\mathrm{K}^{+}$ and $\mathrm{Ca}^{++}$excreted in urine. The treatment also decreased the urinary $\mathrm{pH}$ from $8.0 \pm 0.3$ (control male) and $8.1 \pm 0.4$ (control female) to 7.0 \pm 0.5 and $6.9 \pm 0.3$, respectively. These changes were not significant $(\mathrm{P}>0.05, \mathrm{~N}=8)$.

\section{Effect on carbon tetrachloride-induced hepatic damage in male rats}

Treatment of male Wistar rats with a mixture of $\mathrm{CCl}_{4}$ and paraffin (50:50) in a dose of $1 \mathrm{ml} / \mathrm{kg}$ (i.p.) induced severe damage to the liver on the third day following treatment of the animals (Table 5) as revealed by the significant increases in the hepatic enzymes ALT, AST, alkaline Phosphatase and in the hepatic level of malonaldehyde and the plasma level of bilirubin $(\mathrm{P}<0.01, \mathrm{~N}=8)$. MRD treatment significantly protected the animals against these increases $(\mathrm{P}<0.01, \mathrm{~N}=8)$.

\section{Discussion}

The results of this study clearly demonstrated the functional activity of Myrica rubra fruit juice that is formulated in form of a beverage drink. One of the first observed effects is its stimulant effect on the RBCs and their content of haemoglobin. Such actions were not followed in detail in this study. They may be due to stimulation of erythropoietin. The second observed clear effect is the ability of the drink to decrease both of the total cholesterol and the LDL. The metabolism of these lipids is generally regulated by a family of membrane-bound transcription factors called sterol regulatory element binding proteins, e.g., SREBP-1 [25] and SREBP-2 is reported to regulate the genes involved in cholesterol synthesis [26]. Furthermore, peroxisome prolifertor activated receptors, e.g., PPAR-alpha are involved in the lipids metabolism [27].

MRD is known to contain high concentration of proanthocyanidins [1]. These are condensed tannin polymers composed of various flavan3-ol catechin units. The most available are the reddish procyanidins [2]. MRD constituents may act to suppress lipid metabolism regulatory proteins. Indeed, in a recent study, [7] revealed the ability of oligomeric proanthocyanidins to suppress SPEBP-2 [7] and to increase PPAR- $\alpha$ expression. Another possibility is that the proanthocyanidins and the various poly phenols present in MRD [1,2] may act to suppress fat absorption in the intestine. Previous studies revealed the inherent ability of proanthocyanidins to decrease hyperlipidemia in mouse model type 2 diabetes [9] and in streptozotocin-induced type 1 diabetes in rats [7]. The observed ability of MRD to decrease the levels of the hepatic enzymes during the subchronic treatment may be related to the ability of its proanthocyanidins to elevate the level of the Hepatoprotective glutathione. Indeed, these substances have been shown to elevate the level of glutathione in diabetic rats and mice.

Part of this study revealed the potential of MRD to act as a hepatoprotective against $\mathrm{CCl}_{4}$-induced elevations in the plasma levels of ALT, AST, alkaline Phosphatase, bilirubin and malonaldehyde. The hepatotoxicity of $\mathrm{CCl}_{4}$ is very well studied and is believed to occur as a result of generation of free radicals within the liver [28]. The initial step in this hepatotoxicity is the production of the trichloromethyl radical $\left(-\bullet \mathrm{CCl}_{3}\right)$ via the enzyme cytochrome P450 subtypes (2E1, 2B1, $2 \mathrm{~B} 2$ and $3 A)[29,30]$. The latter radical then interacts with molecular oxygen resulting in the production of the trichloromethyl peroxyl radical $\left(-\bullet \mathrm{O}-\mathrm{O}-\mathrm{CCl}_{3}\right)[30]$. This radical then initiates the peroxidation of the membrane phospholipids and the unsaturated fatty acids. All these peroxides act to damage the cellular components (e.g. mitochondria, endoplasmic reticulum and plasma membranes) with the resultant hepatotoxicity $[28,30,31]$. In addition, $\mathrm{CCl}_{4}$ is reported to release various destructive cytokines such as TNFa [32]. Thus, the observed hepatoprotective effect of MRD may be highly related to the ability of some of its constituents to act as free radical scavengers. Indeed such antioxidant action has been observed for its constituents polyphenols, flavonoids and proanthocyanidins $[6,7,33,34]$.

On a broad basis, the results of this study point clearly to the property of Myrica rubra fruit drink as an anti-anemic, a hypocholesterolemic and a hepatoprotective pointing to its potential as a new functional food.

\section{Acknowledgement}

This project was funded by a grant from Deanship of Research under the number RGP-VPP- 50. This funding is highly appreciated.

\section{References}

1. Fang Z, Zhang M, Tao G, Sun Y, Sun J (2006) Chemical composition of clarified bayberry (Myrica rubra Sieb. et Zucc.) juice sediment. J Agric Food Chem 54: 7710-7716.

2. Saito M, Hoshiyama H, Ariga T, Kataoka S, Yamaji N (1998) Antiulcer activity of grape seed extract and procyanidins. J Agric Food Chem 46: 1460-1464.

3. Tao J, Morikawa T, Toguchida I, Ando S, Matsuda H, et al. (2002) Inhibitors of nitric oxide production from the bark of Myrica rubra: structures of new bipheny 
Citation: Al-Hadiya BM, AlAjmi MF, El Tahir KEH (2013) Myrica rubra Fruit Drink Sub-Chronic Toxicity and Hepatoprotective Effect in Rats. Adv Pharmacoepidem Drug Safety 2: 127. doi:10.4172/2167-1052.1000127

Page 5 of 5

type diarylheptanoid glycosides and taraxerane type triterpene. Bioorg Med Chem 10: 4005-4012.

4. Tong Y, Zhou XM, Wang SJ, Yang Y, Cao YL (2009) Analgesic activity of myricetin isolated from Myrica rubra Sieb. et Zucc. leaves. Arch Pharm Res 32: $527-533$.

5. Wang SJ, Tong Y, Lu S, Yang R, Liao X, et al. (2010) Anti-inflammatory activity of myricetin isolated from Myrica rubra Sieb. et Zucc. leaves. Planta Med 76: $1492-1496$.

6. Dixon RA, Xie DY, Sharma SB (2005) Proanthocyanidins--a final frontier in flavonoid research? New Phytol 165: 9-28.

7. Yokozawa T, Cho EJ, Park CH, Kim JH (2012) Protective Effect of Proanthocyanidin against Diabetic Oxidative Stress. Evid Based Complement Alternat Med 2012: 623879.

8. Cheng HY, Lin TC, Ishimaru K, Yang CM, Wang KC, et al. (2003) In vitro antiviral activity of prodelphinidin B-2 3,3'-di-O-gallate from Myrica rubra. Planta Med 69: 953-956

9. Lee YA, Cho EJ, Yokozawa T (2008) Effects of proanthocyanidin preparations on hyperlipidemia and other biomarkers in mouse model of type 2 diabetes. $J$ Agric Food Chem 56: 7781-7789.

10. Kuo PL, Hsu YL, Lin TC, Lin LT, Lin CC (2004) Induction of apoptosis in human breast adenocarcinoma MCF-7 cells by prodelphinidin B-2 3,3'-di-O-gallate from Myrica rubra via Fas-mediated pathway. J Pharm Pharmacol 56: 13991406.

11. Lee YA, Kim YJ, Cho EJ, Yokozawa T (2007) Ameliorative effects of proanthocyanidin on oxidative stress and inflammation in streptozotocininduced diabetic rats. J Agric Food Chem 55: 9395-9400.

12. Van Assendelft OW (1970) Spectrophotometry of haemoglobin derivatives. Ed. Royal Van Gorem Ltd., Assen. The Netherlands.

13. Trasch H (1984) Quantification of glucose in plasma. Clin Chem 30: 969-972.

14. Bruan HP (1984) Quantitation of total cholesterol in serum and plasma. Clin Chem 30: 991-996.

15. Cartensen CA, Murawaki R, Koller PU (1985) Determination of triglycerides in plasma. J Clin Chem Clin BioChem 30: 608-612.

16. Deneke U (1985) Quantification of G.O.T. (Glutamate oxalo transaminase) in blood and plasma. Clin Chem 31: 921-929.

17. Deneke U, Ritterdorf W (1984) Quantitative determination of ALT (Alanine Transaminase). Clin Chem 30: 1009-1014.

18. Rosalki SB (1993) Multicenter Evaluation of Iso-ALP Test Kit for Measurement of Bone Alkaline Phosphatase Activity in Serum and Plasma. Clin Chem 39: 648-652.
19. Heins M, Heil W, Withold W (1995) Storage of serum or whole blood samples? Effects of time and temperature on 22 serum analytes. Eur J Clin Chem Clin Biochem 33: 231-238.

20. Lum G, Cambizzino R (1974) Determination of total bilirubin. Clin Pathol 61 108-112.

21. Freitag $H$ (1987) Determination of bilirubin in plasma. Clin Chem 33: 1011 1017.

22. Hwang JY, Sandonato L (1969) Determination of calcium using atomic absorption. Anal Chem Acta 48: 183-196.

23. Adams PB, Passmore WO (1966) Quantitation of calcium and $\mathrm{Na}+$ by atomic absorption spectrophotometry. Anal Chem 38: 630-639.

24. Pybus $J$ (1969) Determination of calcium and magnesium in serum and urine by atomic absorption spectrophotometry. Clin Chim Acta 23: 309-317.

25. Yahagi N, Shimano H, Hasty AH, Matsuzaka T, Ide T, et al. (2002) Absence of sterol regulatory element-binding protein-1 (SREBP-1) ameliorates fatty livers but not obesity or insulin resistance in Lep(ob)/Lep(ob) mice. J Biol Chem 277 19353-19357.

26. Shimano H, Yahagi N, Amemiya-Kudo M, Hasty AH, Osuga J, et al. (1999) Sterol regulatory element-binding protein-1 as a key transcription factor for nutritional induction of lipogenic enzyme genes. J Biol Chem 274: 35832 35839.

27. Ferré $P$ (2004) The biology of peroxisome proliferator-activated receptors: relationship with lipid metabolism and insulin sensitivity. Diabetes 53 S43-S50.

28. Ruch RJ, Klaunig JE, Schultz NE, Askari AB, Lacher DA, et al. (1986) Mechanisms of chloroform and carbon tetrachloride toxicity in primary cultured mouse hepatocytes. Environ Health Perspect 69: 301-305.

29. Slater TF (1981) Free radicals as reactive intermediates in tissue injury. Adv Exp Med Biol 136: 575-589.

30. Brattin WJ, Glende EA Jr, Recknagel RO (1985) Pathological mechanisms in carbon tetrachloride hepatotoxicity. J Free Radic Biol Med 1: 27-38.

31. Younes M, Siegers CP (1984) Interrelation between lipid peroxidation and othe hepatotoxic events. Biochem Pharmacol 33: 2001-2003.

32. Weber LW, Boll M, Stampfl A (2003) Hepatotoxicity and mechanism of action of haloalkanes: carbon tetrachloride as a toxicological model. Crit Rev Toxico 33: 105-136.

33. Xie DY, Dixon RA (2005) Proanthocyanidin biosynthesis--still more questions than answers? Phytochemistry 66: 2127-2144.

34. Yang Z, Zheng Y (2009) Effect of high oxygen storage on quality, enzymes and DPPH-RADI activity of Chinese bay. J Agr Food Chem. 